Published in final edited form as:

J Urol. 2010 February ; 183(2): 738-739. doi:10.1016/j.juro.2009.11.076.

\title{
Mucinous Tubular and Spindle Cell Carcinoma of the Kidney
}

\author{
Glen Yang, \\ Department of Urology University of California-San Francisco, San Francisco, California \\ Benjamin N. Breyer, \\ Department of Urology University of California-San Francisco, San Francisco, California \\ Dana A. Weiss, and \\ Department of Urology University of California-San Francisco, San Francisco, California \\ Gregory T. MacLennan \\ Institute of Pathology, University Hospitals of Cleveland, Case Western Reserve University, \\ Cleveland, Ohio
}

\begin{abstract}
Mucinous tubular and spindle cell carcinoma (MTSC) was initially recognized as a distinctive subset of low grade collecting duct carcinomas in $1997,{ }^{1}$ and it was incorporated in the 2004 WHO classification of renal neoplasms under its current name. Although MTSC was regarded as rare, more than 80 cases have been reported. The exact cell of origin is a matter of debate but accumulated evidence suggests that it originates from cells of the loop of Henle or from collecting duct epithelium, with more support for the latter site.
\end{abstract}

MTSC occurs predominantly in females with a 1:4 male-to-female ratio and patient age is 13 to 82 years (mean 53 ). ${ }^{2}$ Although some tumors are symptomatic, the majority are discovered incidentally during abdominal imaging studies. Tumors are 2.2 to $12 \mathrm{~cm}$ (average 6 to 7) in diameter, sharply circumscribed and gray-white, tan or yellow, and sometimes have minimal hemorrhaging and/or necrosis. The cut surfaces are commonly bulging, shiny and mucoid due to the mucin content (fig. 1).

Microscopically MTSC is composed of round, ovoid or elongated tightly packed tubules separated by abundant basophilic extracellular mucin that sometimes has a bubbly myxoid consistency (fig. 2). Focally aggregates of spindled cells may be present, which may simulate sarcomatoid change but without necrosis, mitotic activity or significant nuclear pleomorphism (fig. 2, inset). The mucin stains strongly with Alcian blue at $\mathrm{pH} 2.5$. Tubules are lined by uniform low cuboidal cells with scant cytoplasm, round nuclei of low nuclear grade and absent or inconspicuous nucleoli. Mitotic figures are rare. ${ }^{3}$

The histological spectrum of these tumors has been expanded to include cases in which the spindle cell component rivals or even exceeds the tubular component, as well as those with a relative paucity of mucinous matrix, aggregates of foamy macrophages, small components of well formed papillae, focal clear cell change in tubular cells, focal necrosis, oncocytic tubules, numerous small vacuoles, psammomatous calcification or heterotopic bone formation. ${ }^{3}$ Rarely neuroendocrine differentiation and true sarcomatoid components have been reported. ${ }^{4}$ Cytogenetic analyses and comparative genomic hybridization studies have revealed multiple genetic alterations, including losses of chromosomes 1, 4, 6, 8, 9, 13, 14, 15,18 and $22 .^{2}$

The prognosis for MTSC with classic morphology is generally favorable and complete surgical excision appears to be adequate treatment. These tumors are generally low pathological stage at excision and usually behave indolently. Few cases have demonstrated 
recurrence, regional lymph node metastases or distant metastases. However, 2 of 4 patients with MTSC exhibiting components of true sarcomatoid change died of the disease. ${ }^{4}$

\section{References}

1. MacLennan GT, Farrow GM, Bostwick DG. Low-grade collecting duct carcinoma of the kidney: report of 13 cases of low-grade mucinous tubulocystic renal carcinoma of possible collecting duct origin. Urology. 1997; 50:679. [PubMed: 9372874]

2. MacLennan, GT.; Cheng, L.; Cheng, L. Neoplasms of the kidney. In: Bostwick, DG., editor. Urologic Surgical Pathology. 2nd ed. Mosby Elsevier; Edinburgh: 2008.

3. Fine SW, Argani P, DeMarzo AM, et al. Expanding the histologic spectrum of mucinous tubular and spindle cell carcinoma of the kidney. Am J Surg Pathol. 2006; 30:1554. [PubMed: 17122511]

4. Dhillon J, Amin MB, Selbs E, et al. Mucinous tubular and spindle cell carcinoma of the kidney with sarcomatoid change. Am J Surg Pathol. 2009; 33:44. [PubMed: 18941398] 


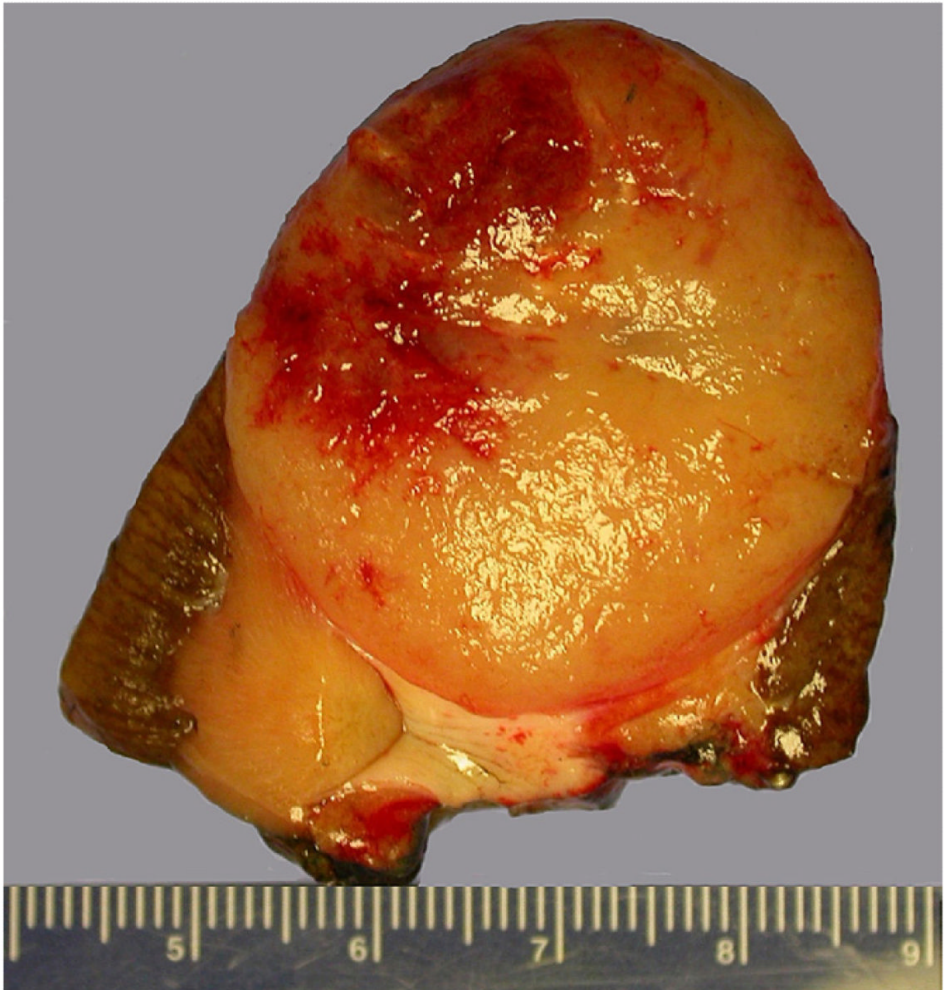

Figure 1.

MTSC exhibits bulging shiny mucoid cut surface. 


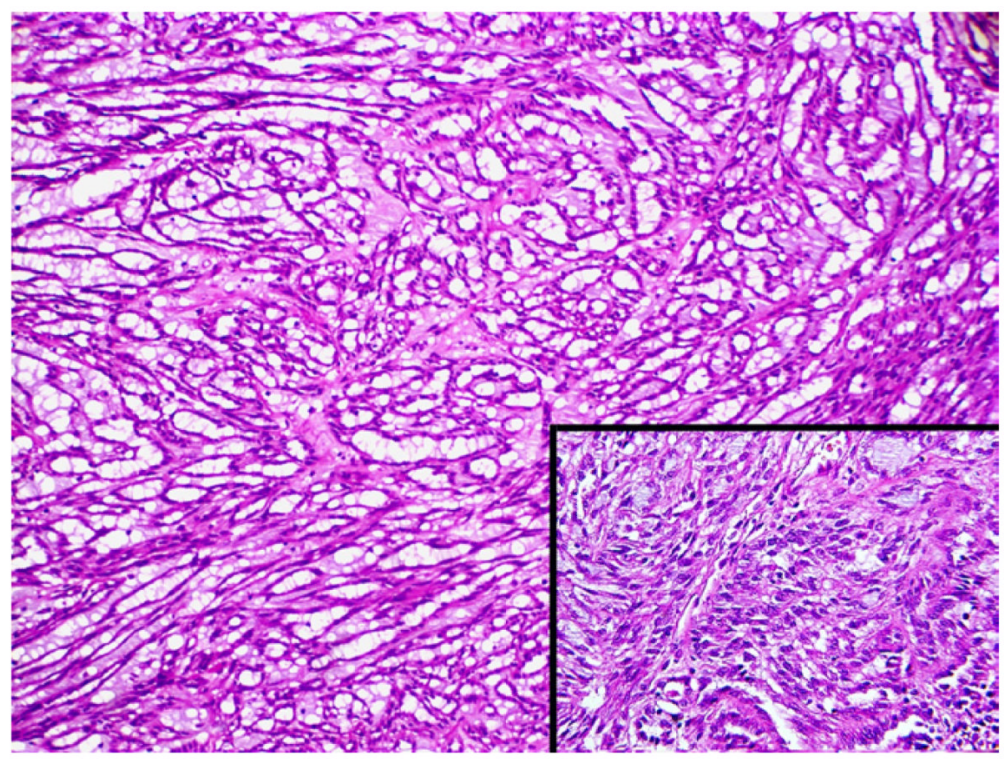

Figure 2.

MTSC composed of tightly packed elongated tubules separated by abundant basophilic extracellular mucin with bubbly myxoid consistency. Aggregates of spindled cells may be present (inset). 